\title{
Comparison of Internet Usage Habits in Two Generations of Higher Education Students. A Case Study
}

Rosalina Babo ${ }^{1}$, Carla Teixeira Lopes ${ }^{2}$, Ana Cláudia Rodrigues ${ }^{3}$, Mário Pinto ${ }^{3}$, Ricardo Queirós ${ }^{3}$, and Paulo Coelho de Oliveira ${ }^{4}$ ${ }^{1}$ ISCAP, ${ }^{2}$ ESTSP, ${ }^{3}$ ESEIG, ${ }^{4}$ ISEP

Instituto Politécnico do Porto

This study aims to understand the importance of technologies like the Internet and Learning Management Systems on Higher Education students' learning activities. We investigate how much and how students use the Internet and how important these technologies are to Polytechnic of Porto (IPP)' students. This population's habits were obtained through a questionnaire that was answered by $11 \%$ of all IPP's students. Our analysis is focused not only on the global Internet usage profile of IPP's students, but also on the differences between the students born before and after 1980. International trends are confirmed in this Portuguese Higher Education institution.

\section{Sample distribution across scientific fields}

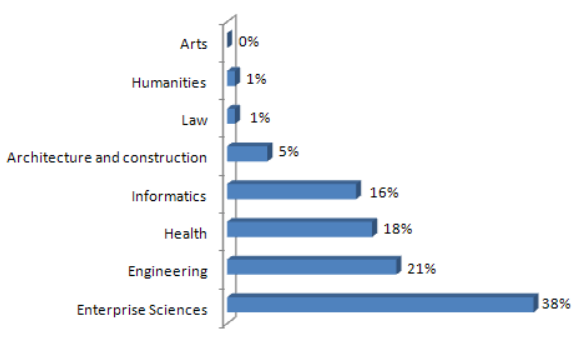

\section{Distributions across generations}

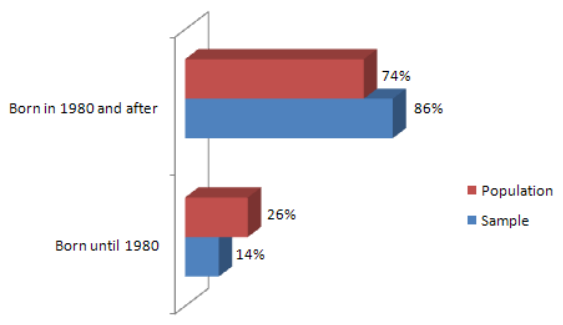

\section{Daily average connection to Internet}

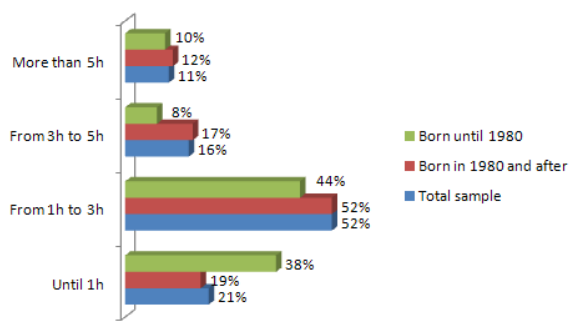

\section{Most Used Internet's Tools}

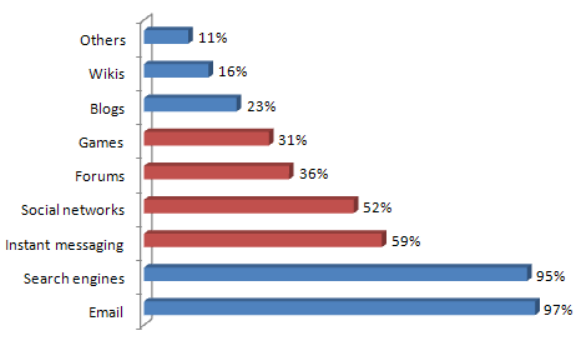

- (These tools are, statistically more used by students born after 1980: Instant messaging $(p \cong 0,000)$, Social networks $(p \cong 0,000)$, Forums $(p=0,009)$ and Games $(p \cong 0,000)$ use).

Internet usage main reasons older and younger students: web 1.0 vs web 2.0 orientation

\begin{tabular}{|c|c|c|c|c|}
\hline Reasons for using internet & & Total & $\begin{array}{c}\text { Born } \\
<1980\end{array}$ & $\begin{array}{l}\text { Born } \\
>=1980\end{array}$ \\
\hline Research concerning class works / study & & $91 \%$ & & \\
\hline Access documents in Moodle or another LMS & $75 \%$ & $p=0,001$ & $85 \%$ & $73 \%$ \\
\hline Email exchange & $73 \%$ & $\mathrm{p} \cong 0,000$ & $87 \%$ & $70 \%$ \\
\hline Connect with friends & $71 \%$ & $\mathrm{p} \cong 0,000$ & $8 \%$ & $63 \%$ \\
\hline Read newspapers, magazines and portals & $51 \%$ & $\mathrm{p} \cong 0,000$ & $68 \%$ & $49 \%$ \\
\hline Download music or films & $50 \%$ & $\mathrm{p} \cong 0,000$ & $17 \%$ & $55 \%$ \\
\hline Search info (other than school issues) & $44 \%$ & $p \cong 0,000$ & $56 \%$ & $42 \%$ \\
\hline Share information (documents, music, films, etc.) & $27 \%$ & $p=0,001$ & $3 \%$ & $25 \%$ \\
\hline Access friends social networks & $24 \%$ & $\mathrm{p} \cong 0,000$ & $2 \%$ & $21 \%$ \\
\hline Games & $18 \%$ & $p \cong 0,000$ & $1 \%$ & $17 \%$ \\
\hline Forums usage (post or read) & $17 \%$ & $p=0,031$ & $2 \%$ & $15 \%$ \\
\hline Shop & $11 \%$ & $p=0,019$ & $2 \%$ & $9 \%$ \\
\hline Blog usage (post or visit others) & & $9 \%$ & & \\
\hline Search new friends / acquaintances & & $6 \%$ & & \\
\hline Others & & $2 \%$ & & \\
\hline
\end{tabular}

\section{Moodle's role in learning process}

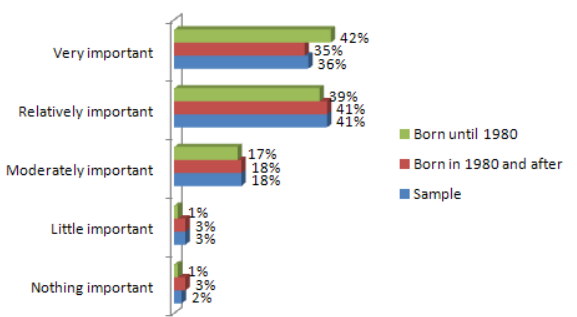

\section{Final Remarks}

\section{IPP's students profile usage of Internet}

$>$ Internet is accessed 1 to 3 hours a day; Email and synchronous communication are the tools used daily; this last one, is more frequently used among the younger students

$>$ Internet is primarily used to search information, access Moodle eLearning platform, exchange emails, and to talk with friends

$>$ Most students have, at least, profile at one social network, and $33 \%$ usually meet new people through these platforms

LMS's platform students usage (Moodle as $98 \%$ coverage in IPP)

$>$ Daily accessed; Students find no difficulties in the use of Moodle and think this LMS is an important tool in their learning process

$>$ Web 2.0 tools (wikis, forums or blogs) are scarcely used by teachers Future research

$>$ Replicate this study every 2 years, and use these data as an Internet Usage Observatory $>$ To study Internet's usage habits of all IPP's population and establish orientation guidelines to a successful exploit of Internet technologies in the Higher Education learning process 